\title{
KAJI EKSPERIMENTAL PEMANFAATAN KALOR BUANGAN KONDENSOR UNTUK KEBUTUHAN PENGERINGAN
}

\author{
Rikhard Ufie \\ E-mail: rikhardufie@gmail.com \\ Jurusan Teknik Mesin Fakultas Teknik Universitas Pattimura
}

\begin{abstract}
ABSTRAK
Kaji eksperimental pemanfaatan kalor buangan kondensor untuk kebutuhan pengeringan telah diteliti. Proses pendinginan dengan mesin refrigerasi siklus uap dimana kalor yang masuk ke sistem berasal dari beban pendinginan ditambah kalor hasil kerja kompresi dari kompresor biasanya dibuang ke lingkungan. Penelitian ini akan mengkaji kemungkinan pemanfaatan kalor yang dibuang ke lingkungan tersebut dengan cara pengembangan prototipe pendinginan dan pengeringan terpadu. Selain itu diharapkan akan diperoleh efek pendinginan bagi produk tertentu melalui kerja evaporator dan efek pengeringan melalui kerja kondensor. Unit pendinginan dan pengeringan terpadu menggunakan Freon R-22 dengan daya kompresor $0.5 \mathrm{hp}(0.368 \mathrm{~kW})$ dengan produk pendinginan yakni massa air 32 $\mathrm{kg}$. Hasil penelitian memperlihatkan pada temperatur kondensasi $48.3{ }^{\circ} \mathrm{C}$ diperoleh temperatur lemari pengering ratarata $37.8^{\circ} \mathrm{C}$ dengan kapasitas pemanasan $914.6 \mathrm{~W}$ yaitu dimana ratio kompresi 6.98 dengan tekanan evaporasi 38.6 psia dan temperatur evaporasi $-18.5^{\circ} \mathrm{C}$. Pada beban kerja sebesar $613.057 \mathrm{~W}$ diperoleh daya kompresi terpakai $307.6 \mathrm{~W}$ dengan COP sebesar 1.99, sedangkan laju kalor yang dilepas kondensor sebesar $920.72 \mathrm{~W}$.
\end{abstract}

Kata kunci : unit terpadu, refrigerator, kondensor, COP

\section{PENDAHULUAN}

Produk perikanan/pertanian dalam arti luas berupa bahan makanan (foods), mencakup buah-buahan, sayur-sayuran, ikan, daging, dan berbagai bahan olahan lainnya, umumnya akan mengalami pembusukan jika terus dibiarkan berada pada temperatur lingkungan. Untuk memperpanjang umur penyimpanan (life storage) dari berbagai bahan dimakud dilakukan tindakan pengawetan, melalui upaya pendingin maupun pengeringan.

Pendinginan produk dilakukan antara lain dengan menerapkan sistem refrigerasi mekanik siklus kompresi uap dimana produk ditempatkan pada lemari pendingin yang didinginkan oleh evaporator. Pada sistem pendinginan ini masukan energi yang berasal dari produk yang hendak didinginkan dan juga kompresor, dilepas ke lingkungan melalui kerja kondensor.

Semakin besar kalor yang diserap dari produk dan semakin besar penggunaan energi yang diberikan kepada kompresor, semakin besar pula jumlah kalor yang terbuang.

Untuk setiap penggunaan mesin pendingin siklus kompresi uap dengan demikian terdapat potensi kalor terbuang yang besar yang seharusnya dapat dimanfaatkan kembali (recovery) antara lain bagi suatu proses pengeringan.

Melalui penelitian ini dikaji kemungkinan memanfaatkan kembali kalor yang dilepas kondesor melalui suatu prototipe pendingin dan pengering secara terpadu yang dijalankan dengan satu kompresor, sehingga selain diperoleh efek pendinginan bagi produk tertentu di satu pihak, diperoleh pula efek pengeringan produk di pihak lain.

Tujuan dari penelitan ini yaitu untuk mengetahui berapa suhu dan kapasitas pengeringan rata-rata yang dapat diperoleh serta berapa besar variabel kerja unit pendingin sesuai kondisi kerja siklus kompresi uap yang terjadi.

\section{KAJIAN TEORI DAN METODE \\ 1. Perhitungan Beban Pendinginan \\ a. Beban Transmisi}

Beban transmisi kalor yang masuk melalui dinding ruangan pendingin, dapat dihitung dengan persamaan (ASRHAE, 1990):

$$
q_{\text {trans. }}=U A \Delta t
$$

di mana:

$q_{\text {trans.C }}=$ beban transmisi kalor melalui dinding kotak

pendingin, $\mathrm{kW}$

$A_{C}=$ luas bidang perpindahan panas kotak pendingin, $\mathrm{m}^{2}$

$\Delta t_{C}=$ beda antara temperatur udara luar dan temperatur ruang pendingin, ${ }^{\circ} \mathrm{C}$ 
$U_{C}=$ koefisien perpindahan kalor menyeluruh dari dinding kotak pendingin yang dihitung dengan persamaan :

di mana:

$$
U_{C}=\frac{1}{1 / f o+\sum_{i=1}^{n} x_{i} / k_{i}+1 / h_{i}}
$$

$f_{o}=$ konduktivitas film dinding luar, $\mathrm{W} /\left(\mathrm{m}^{2} \mathrm{C}\right)$

$x_{i}=$ tebal lapisan ke i, $\mathrm{m}$

$k_{i}=$ konduktivitas lapisan ke i, . W/(mC)

$h_{i}=$ koefisien perpindahan panas konveksi dinding dalam, $\mathrm{W} /\left(\mathrm{m}^{2} \cdot \mathrm{C}\right)$.

\section{b. Beban Produk}

1. Kalor sensibel yang dipindahkan untuk mendinginkan produk dari temperatur lingkungan ke titik beku, yang dihitung dengan persamaan (ASRHAE, 1990):

$$
Q_{C l}=m_{c} c_{1}\left(t_{1}-t_{f}\right)
$$

2. Kalor laten pembekuan produk, yang dihitung dengan persamaan (ASRHAE, 1990):

$$
Q_{C 2}=m_{c} h_{s f}
$$

3. Kalor sensibel yang dipindahkan untuk mendinginkan produk dari titik beku ke temperatur penyimpanan titik beku, yang dihitung dengan rumus(ASRHAE, 1990):

$$
Q_{c 3}=m_{c} \cdot c_{2}\left(t_{f}-t_{s f}\right)
$$

dimana:

$$
\begin{aligned}
& \mathrm{Q}_{\mathrm{c} 1}, \mathrm{Q}_{\mathrm{c} 2}, \mathrm{Q}_{\mathrm{c} 3}=\begin{array}{l}
\text { kalor sensibel yang } \\
\text { dipindahkan. } \mathrm{kJ}
\end{array} \\
& \mathrm{m}_{\mathrm{c}}= \text { massa produk, } \mathrm{kg} \\
& \mathrm{h}_{\mathrm{sf}} \text { kalor laten pembekuan produk, } \mathrm{kJ} / \mathrm{kg} \\
& \mathrm{c}_{1}= \text { kalor spesifik produk di atas } \\
& \text { pembekuan, } \mathrm{kJ} /\left(\mathrm{kg} .{ }^{\circ} \mathrm{C}\right) \\
& \mathrm{c}_{2}= \text { kalor spesifik produk di atas } \\
& \text { pembekuan, } \mathrm{kJ} /\left(\mathrm{kg} .{ }^{\circ} \mathrm{C}\right) \\
& t_{1}= \text { temperatur lingkungan, }{ }^{\circ} \mathrm{C} \\
& t_{f}= \text { temperatur beku produk, }{ }^{\circ} \mathrm{C} \\
& t_{s f}= \text { temperatur beku produk, }{ }^{\circ} \mathrm{C}
\end{aligned}
$$

4. Beban produk keseluruhan diperoleh:

$$
q_{\text {prodC }}=\frac{Q_{c 1}+Q_{c 2}+Q_{c 3}}{3600 n}
$$

di mana:

$q_{\text {prodC }}=$ beban pengeringan produk, $\mathrm{kW}$

$n \quad=$ waktu pengeringan, jam

\section{c. Total Beban Pendinginan}

Total beban pendingin sebagai jumlah keseluruhan kalor yang harus dipindahkan oleh unit pendingin, dihitung dengan rumus (ASRHAE, 1990):

$$
\dot{Q}_{c}=\left(q_{\text {trans }}+q_{\text {prodc }}\right) \cdot F_{s}
$$

di mana:

$$
\begin{aligned}
& \dot{Q}_{C}=\text { Beban pendingin, } \mathrm{W} \\
& F_{S}=\text { factor koreksi }
\end{aligned}
$$

\section{Perhitungan Beban Pengeringan}

\section{a. Beban Transmisi}

Beban transmisi berupa kalor yang keluar melalui dinding pengering, dihitung dengan persamaan:

di mana:

$$
q_{\text {trans }}=U A \Delta t
$$

$q_{\text {trans }}=$ beban transmisi kalor melalui dinding lemari pengering, $\mathrm{kW}$

$A=$ luas bidang perpindahan panas lemari pengering, $\mathrm{m}^{2}$

$\Delta t_{H}=$ beda antara temperatur udara luar dan temperatur ruang pengering, ${ }^{\circ} \mathrm{C}$

$U_{H}=$ koefisien perpindahan kalor menyeluruh dari dinding pengering.

\section{b. Beban Produk}

Kalor sensibel yang dipindahkan untuk mengeringkan produk dari temperatur awal ke temperatur pengeringan, yang dihitung dengan persamaan:

di mana:

$$
Q_{H}=m_{H} c_{H}\left(t_{1}-t_{f}\right)
$$

$Q_{H} \quad=\quad$ kalor s yang dipindahkan, $\mathrm{kJ}$

$m_{c}=$ massa produk, $\mathrm{kg}$

$c_{H}=$ kalor spesifik produk, $\mathrm{kJ} /(\mathrm{kg}$. C)

$t_{H i}=$ temperatur awal produk, ${ }^{\circ} \mathrm{C}$

$t_{H f}=$ temperatur akhir produk, ${ }^{\circ} \mathrm{C}$

Beban produk keseluruhan diperoleh:

$$
\dot{Q}_{H}=\frac{Q_{c 1}+Q_{c 2}+Q_{c 3}}{3600 n}
$$

di mana:

$\dot{Q}_{H}=$ beban pendinginan produk, $\mathrm{kW}$

$n$ = waktu pendinginan, jam

\section{Refrigerasi Siklus Kompresi Uap}

Kondisi kerja mesin regrigerasi siklus kompresi uap dapat dinyatakan sesuai perubahan tingkat keadaan refigeran sebagai fluida kerja, dalam suatu skema diagram tekanan-entalpi (p-h), seperti diperlihatkan pada Gambar 1. 


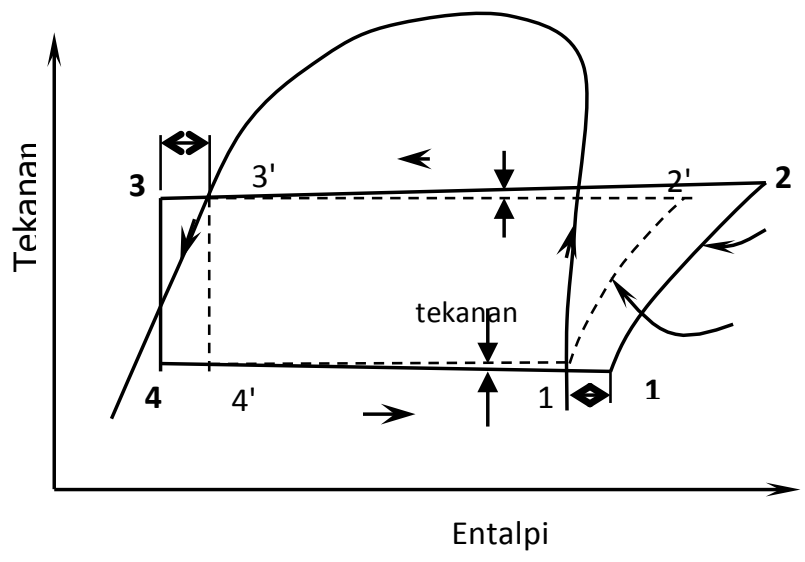

Gambar 1. Siklus Kompresi Uap

Proses (1-2) adalah proses kompresi dimana uap refrigeran bertekanan rendah dari evaporator dikompresikan oleh kompresor hingga mencapai tekanan dan temperatur di atas kondisi lingkungan; proses (2-3) adalah proses kondensasi dimana refrigeran diembunkan dalam kondensor dengan cara melepas kalor ke lingkungan; proses (3-4) adalah proses ekspansi dimana refrigeran bertekanan tinggi diturunkan tekanannya agar mencapai temperatur evaporasi yang dikehendaki; dan proses (4-1) yaitu proses evaporasi dimana refrigeran menguap dengan menyerap kalor yang ruangan yang hendak didinginkan.

\subsection{Perhitungan Variabel Kerja Sistem}

\section{a. Dampak Refrigerasi}

Kalor yang harus diserap oleh evaporator dari kotak pendingin adalah sama dengan total beban pendingingan $\left(\dot{Q}_{C}\right)$; sedangkan dampak refrigerasi dihitung sebagai selisih entalpi pada titik 1 dengan titik 4, yaitu (ASRHAE, 1990):

$$
q_{c}=\left(h_{1}-h_{4}\right)
$$

di mana:

$h_{1}=$ entalpi pada titik $1, \mathrm{~kJ} / \mathrm{kg}$.

$h_{4}=$ entalpi pada titik $4, \mathrm{~kJ} / \mathrm{kg}$.

\section{b. Perhitungan Laju Alir Massa Refrigeran}

Laju aliran massa refrigeran dihitung dengan persamaan (ASRHAE, 1990):

$$
\dot{m}=\frac{\dot{Q}_{c}}{\left(h_{1}-h_{4}\right)}
$$

di mana:

$\dot{Q}_{C}=$ kalor yang diserap evaporator atau beban pendinginan, $\mathrm{kW}$

$m=$ laju aliran massa refrigeran, $\mathrm{kg} / \mathrm{s}$.

\section{c. Perhitungan Daya Kompresi}

Daya kompresi isentropik dihitung dengan rumus:

$$
\mathrm{W}_{\mathrm{k}}=m\left(h_{2}-h_{1}\right)
$$

di mana:

$\dot{m}=$ laju aliran massa refrigeran, $\mathrm{kg} / \mathrm{s}$.

$h_{2}=$ entalpi pada tingkat keadaan $2, \mathrm{~kJ} / \mathrm{kg}$.

$h_{l}=$ entalpi pada tingkat keadaan $1, \mathrm{~kJ} / \mathrm{kg}$.

\section{d. Perhitungan Koefisien Performansi (COP) sisi Refrigerasi}

Koefisien Performasi sisi refrigerasi (Coefficient of Performance, $C O P$ ) dihitung dengan persamaan:

$$
C O P=\dot{Q}_{c} / \dot{W}_{k}
$$

\section{e. Perhitungan Kalor yang dilepas oleh Kondensor}

Panas yang dilepaskan oleh kondensor ke lemari pengering dihitung dengan dengan persamaan:

$$
\dot{Q_{H}}=\dot{m}\left(h_{2}-h_{3}\right)
$$

di mana:

$\dot{m}=$ laju aliran massa refrigeran, $\mathrm{kg} / \mathrm{s}$.

$h_{2}=$ entalpi pada titik $2, \mathrm{~kJ} / \mathrm{kg}$.

$h_{3}=$ entalpi pada titik $3, \mathrm{~kJ} / \mathrm{kg}$.

\subsection{Skema Rancangan}

Skema prototipe unit pendingin dan pengering terpadu ditunjukkan pada Gambar 2 yang terdiri dari: (1) Lemari Pendingin yang di dalamnya dipasang koil evaporator mengikuti susunan rak lemari pendingin; (2) Lemari Pengering yang di dalamnya dipasang koil kondensor mengikuti susunan rak lemari pengering; (3) Kompresor tunggal yang digunakan untuk menjalankan unit pendingin dan pengering secara serempak; (4) Alat ekspansi berupa pipa kapiler dan (5) Filter-dryer.

Untuk penelitian awal ini unit lemari pendingin yang digunakan berukuran panjang-dalam $0,72 \mathrm{~m}$, lebar-dalam $0,44 \mathrm{~m}$ dan tinggi-dalam $0,52 \mathrm{~m}$ dan berupa dinding komposit dengan susunan seperti terdapat pada Tabel 1. 


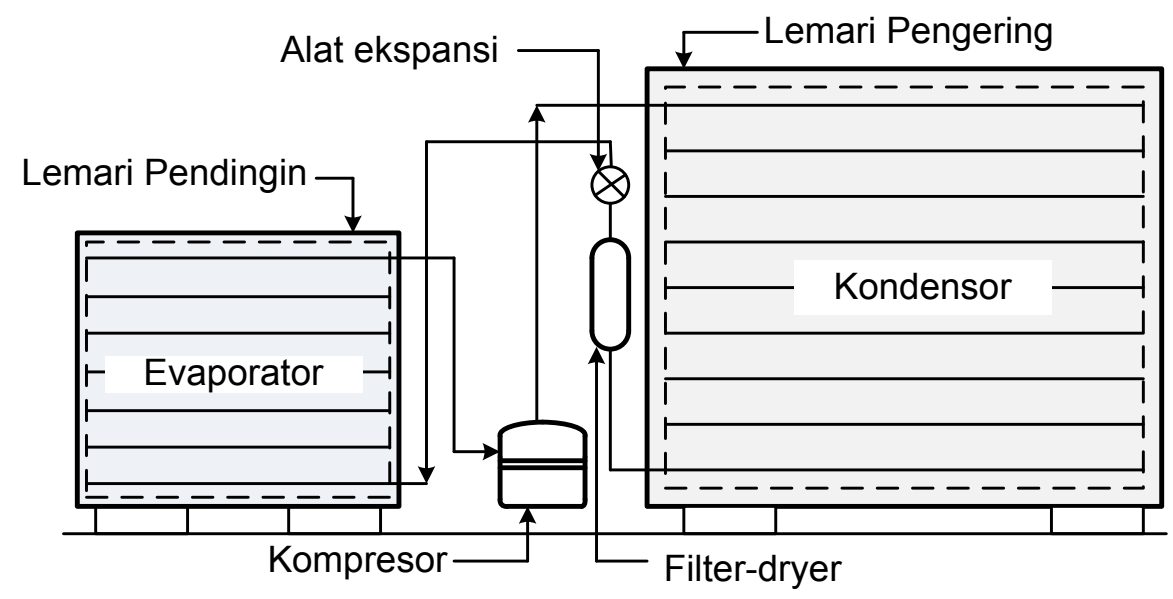

Gambar 2. Unit Pengering - Pendingin Terpadu

Tabel 1 Susunan Dinding Komposit Unit Pendingin

\begin{tabular}{|c|c|c|c|}
\hline No. & $\begin{array}{c}\text { Dinding } \\
\text { kompsit }\end{array}$ & Tebal, $\mathrm{m}$ & $\begin{array}{c}\text { Konduktivitas } \\
\text { Termal } \\
\mathrm{k}, \mathrm{W} /(\mathrm{m} . \mathrm{K})\end{array}$ \\
\hline 1 & Fiber glass, & 0.001 & 0.038 \\
\hline 2 & plywood, & 0.008 & 0,12 \\
\hline 3 & Stereofoam, & 0.04 & 0.0039 \\
\hline 4 & Pelat, & 0.001 & 9.2 \\
\hline 5 & Fiber glass & 0,001 & 0,038 \\
\hline
\end{tabular}

Unit pemanas berbentuk lemari dimana ditempatkan sebanyak 8 susun pipa kondensor untuk pemanasan tiap rak pengering. Unit pemanas ini dirancang-bangun dengan ukuran panjang-dalam $1 \mathrm{~m}$, lebar-dalam $0,57 \mathrm{~m}$ dan tinggi-dalam 0,9 m.dan berupa dinding komposit dengan susunan seperti terdapat pada Tabel 2.

Tabel 2 Susunan Dinding Komposit Unit Pemanas

\begin{tabular}{|c|c|c|c|}
\hline No. & $\begin{array}{c}\text { Dinding } \\
\text { komposit }\end{array}$ & Tebal, $\mathrm{m}$ & $\begin{array}{c}\text { Konduktivitas } \\
\text { Termal } \\
\mathrm{k}, \mathrm{W} /(\mathrm{m} . \mathrm{K})\end{array}$ \\
\hline 1 & Multipleks & 0.008 & 0.12 \\
\hline 3 & $\begin{array}{c}\text { Karet } \\
\text { Busa/Stereofoam }\end{array}$ & 0.04 & 0.0039 \\
\hline 4 & Pelat aluminium & 0.001 & 9.2 \\
\hline
\end{tabular}

Untuk unit terpadu ini digunakan kompesor R-22 berdaya $0,5 \mathrm{hp}(0,368 \mathrm{~kW})$ yang umumnya digunakan untuk AC, sedangkan alat ekspansi yang digunakan adalah berupa pipa kapiler yang diperpanjang untuk memungkinka diperolehnya rasio kompresi yang cukup besar agar temperatur evaporasi yang dapat diperoleh di bawah temperatur beku air dan temperatur kondensasi tetapi cukup tinggi untuk mendukung proses pemanasan dalam lemari pengering.

\section{HASIL DAN PEMBAHASAN}

\section{Kapasitas Pendinginan dan Pemanasan}

Hasil perhitungan kapasitas pendinginan dan pemanasan yang terdiri dari beban transmisi dan beban produk ditunjukkan pad Tabel 3 dan Tabel 4.

Perhitungan kalor transmisi dilakukan untuk harga temperatur lingkungan rata-rata sebesar $27,6{ }^{\circ} \mathrm{C}$ untuk pengujian selama 60 menit. Sedangkan perhitungan kapasitas pendinginan maupun pengeringan didasarkan pada perubahan temperatur air masing-masing pada colbox dan lemari pengering dengan nilai kalor spesifik air konstan.

Sesuai hasil perhitungan, maka kapasitas pendinginan dan pengeringan diperoleh masingmasing sebesar 613,57 W dan 914,6 W.

Tabel 3 Hasil Perhitungan Beban Pendinginan

\begin{tabular}{|c|c|c|c|}
\hline No. & $\begin{array}{c}\text { Beban } \\
\text { Pendinginan } \\
\text { Coolbox }\end{array}$ & Nilai & Satuan \\
\hline 1 & Lama pengujian, $\mathrm{t}$ & 60 & menit \\
\hline 2 & $\begin{array}{c}\text { Laju kalor } \\
\text { transmisi, Qtrans }\end{array}$ & 14,647 & $\mathrm{~W}$ \\
\hline 3 & $\begin{array}{c}\text { Q pendinginan air } \\
\text { total Qair }\end{array}$ & 2154276,0 & $\mathrm{~W}$ \\
\hline 4 & q.air & 598,4 & $\mathrm{~W}$ \\
\hline 5 & Q pendinginan total & 613,06 & $\mathrm{~W}$ \\
\hline
\end{tabular}


Tabel 4. Hasil Perhitungan Beban Pemanasan

\begin{tabular}{|c|c|c|c|}
\hline No. & Beban pemanasan & Nilai & Satuan \\
\hline 1 & Lama pengujian, $\mathrm{t}$ & 60 & menit \\
\hline 2 & $\begin{array}{c}\text { Laju kalor } \\
\text { transmisi, Qtrans }\end{array}$ & 20,877 & $\mathrm{~W}$ \\
\hline 3 & $\begin{array}{c}\text { Q pemanasan air } \\
\text { total }\end{array}$ & 3217402,8 & $\mathrm{~J}$ \\
\hline 4 & $\begin{array}{c}\text { Laju kalor } \\
\text { pemanasan air Q̇air }\end{array}$ & 893,72 & $\mathrm{~W}$ \\
\hline 5 & $\begin{array}{c}\text { Beban Pengeringan, } \\
\text { Q } \mathrm{k}\end{array}$ & 914,6 & $\mathrm{~W}$ \\
\hline 6 & $\begin{array}{c}\text { Temperatur } \\
\text { pengeringan rata- } \\
\text { rata Tp }\end{array}$ & 37.8 & ${ }^{\circ} \mathrm{C}$ \\
\hline
\end{tabular}

\section{a. Hasil Pengukuran Variabel Kerja Unit Pendingin-Pengering Terpadu}

Hasil Pengukuran variabel kerja rata-rata unit pendingin-pengering terpadu ini pada kondisi beban maksimum selama 60 menit ditunjukan pada Tabel 5.

Terlihat bahwa pada temperatur evaporasi ratarata sebear $-18,5^{\circ} \mathrm{C}$ yang dicapai pada tekanan sebesar 38,6 psia, diperoleh temperatur kondensasi rata-rata sebesar $48,3^{\circ} \mathrm{C}$ yang dicapai pada tekanan 269,7 psia. Dengan perbedaan tekanan ini maka rasio kompresi diperoleh sebesar 6,98. Dari hasil pengukuran diperoleh temperatur awal dan akhir kompresi masing-masing sebesar $10,1^{\circ} \mathrm{C}$ dan $137,8^{\circ} \mathrm{C}$, sedangkan temperatur akhir kondensasi sebesar $40,1^{\circ} \mathrm{C}$. Dari perhitungan variabel kerja terlihat bahwa pada proses pendinginan dengan beban pendinginan sebesar 613.057W dan dampak refrigeasi sebesar 161.8 $\mathrm{kJ} / \mathrm{kg}$, diperoleh laju alir massa refrigeran sebesar $0,003789 \mathrm{~kg} / \mathrm{s}$. Berdasarkan besar laju lair massa refrigeran ini, maka pada proses pengeringan diperoleh laju kalor yang dilepas oleh kondensor sebesar 920,72 W sedikit lebih tinggi dibanding hasil perhitungan beban pengeringan yang ditunjukkan pada Tabel 5.4.
Tabel 5. Hasil Pengukuran dan Perhitungan Variabel Kerja Unit Pendingin-pengering Terpadu

\begin{tabular}{|c|c|c|c|}
\hline No. & Variabel/Parameter & Besar & Satuan \\
\hline 1 & Massa air & 32 & $\mathrm{~kg}$ \\
\hline 2 & $\begin{array}{l}\text { Tekanan kondensasi } \\
\mathrm{p}_{2}=\mathrm{p}_{3}\end{array}$ & 267.7 & psia \\
\hline 3 & $\begin{array}{c}\text { Tekanan evaporasi } \\
\mathrm{p}_{1}=\mathrm{p}_{4}\end{array}$ & 38,6 & psia \\
\hline 4 & Rasio Kompresi, $C_{R}$ & 6,98 & \\
\hline 5 & $\begin{array}{c}\text { Temperatur evaporasi, } \\
\mathrm{T}_{\text {eva }}\end{array}$ & -18.5 & ${ }^{\circ} \mathrm{C}$ \\
\hline 6 & $\begin{array}{l}\text { Temperatur awal } \\
\text { kompresi, } \mathrm{T}_{1}\end{array}$ & 10.00 & ${ }^{\circ} \mathrm{C}$ \\
\hline 7 & $\begin{array}{l}\text { Temperatur akhir } \\
\text { kompresi, } \mathrm{T}_{2}\end{array}$ & 137.8 & ${ }^{\circ} \mathrm{C}$ \\
\hline 8 & $\begin{array}{c}\text { Temperatur kondensasi, } \\
\mathrm{T}_{\text {kond }} \\
\end{array}$ & 48.3 & ${ }^{\circ} \mathrm{C}$ \\
\hline 9 & $\begin{array}{l}\text { Temperatur akhir } \\
\text { kondensasi, } \mathrm{T}_{3}\end{array}$ & 40,1 & ${ }^{\circ} \mathrm{C}$ \\
\hline 10 & $\begin{array}{c}\text { Beban Pendinginan, } \\
\text { Q-evap }\end{array}$ & 613,06 & $\mathrm{~kW}$ \\
\hline 11 & $\begin{array}{c}\text { Entalpi awal kompresi, } \\
\mathrm{h}_{1}\end{array}$ & 416,7 & $\mathrm{~kJ} / \mathrm{kg}$ \\
\hline 12 & $\begin{array}{l}\text { Entalpi akhir kompresi, } \\
\mathrm{h}_{2}\end{array}$ & 497,9 & $\mathrm{~kJ} / \mathrm{kg}$ \\
\hline 13 & $\begin{array}{c}\text { Entalpi akhir } \\
\text { kondensasi, } \mathrm{h}_{3}=\mathrm{h}_{4}\end{array}$ & 254,9 & $\mathrm{~kJ} / \mathrm{kg}$ \\
\hline 15 & $\begin{array}{c}\text { Entropi awal dan akhir } \\
\text { kompresi isentropik } \\
\mathrm{s}_{1}=\mathrm{s}_{2 \mathrm{~s}}\end{array}$ & 1.848 & $\mathrm{~kJ} /(\mathrm{K} . \mathrm{kg})$ \\
\hline 16 & $\begin{array}{c}\text { Entropi akhir kompresi, } \\
\mathrm{s}_{2}\end{array}$ & 1.910 & $\mathrm{~kJ} /(\mathrm{K} \cdot \mathrm{kg})$ \\
\hline 17 & Dampak refigerasi, $\mathrm{q}_{0}$ & 161.8 & $\mathrm{~kJ} / \mathrm{kg}$ \\
\hline 18 & $\begin{array}{l}\text { Kalor spesifik yang } \\
\text { dilepas kondensor, } \mathrm{q}_{\mathrm{k}}\end{array}$ & 243.0 & $\mathrm{~kJ} / \mathrm{kg}$ \\
\hline 19 & $\begin{array}{l}\text { Laju alir massa } \\
\text { refrigeran, m-dot }\end{array}$ & 0.003789 & $\mathrm{~kg} / \mathrm{s}$ \\
\hline 20 & $\begin{array}{l}\text { Kalor yang dilepas } \\
\text { Kondensor, } \mathrm{Q}_{\mathrm{k}}\end{array}$ & 0,92072 & $\mathrm{~kW}$ \\
\hline 21 & $\begin{array}{c}\text { Kerja kompresi aktual } \\
\mathrm{W}_{\mathrm{k}}\end{array}$ & 81.2 & $\mathrm{~kJ} / \mathrm{kg}$ \\
\hline 22 & $\begin{array}{c}\text { Daya kompresi aktual, } \\
\mathrm{W}_{\mathrm{k}}\end{array}$ & 0,30766 & $\mathrm{~kW}$ \\
\hline 23 & $\begin{array}{c}\text { Coefficient of } \\
\text { Performance, COP }\end{array}$ & 1,99 & - \\
\hline
\end{tabular}

\section{KESIMPULAN}

Dari hasil pengujian dengan prototipe pendingin dan pengering terpadu yang digunakan dapatlah disimpulkan beberapa hal sebagai berikut: 
(1) Pada temperatur kondensasi $48,3{ }^{\circ} \mathrm{C}$, temperatur lemari pengering rata-rata dapat dicapai sebesar $37,8{ }^{\circ} \mathrm{C}$ dengan kapasitas pemanasan sebesar 914,6 W yaitu kondisi dimana kompresor bekerja rasio kompresi 6,98 dengan tekanan evaporasi sebesar 38,6 psia dengan temperatur evaporasi $-18,5{ }^{\circ} \mathrm{C}$

(2) Pada beban kerja sebesar $613,057 \mathrm{~W}$, daya kompresi yang terpakai adalah sebesar $307,6 \mathrm{~W}$, sehingga COP refrigerasi diperoleh sebesar 1,99. Sedangkan laju kalor yang dilepas kondesor adalah sebesar 920,72 W.

\section{DAFTAR PUSTAKA}

ASHRAE, (1990): Fundamentals Handbook, American Society of Heating, Refrigerating and Air-Contioning Enggineer, Inc. Atlanta.

Arora, (2001): Refrigeration and Air Conditioning. McGraw-Hill International Edition, Boston/Singapore.

Incropera F.P., and De Witt, D.P., (1990): Fundamentals of Heat and Mass Transfer. $3^{\text {rd }}$ ed. John Wiley\&Sons. New York..

Stoecker W.F, and J.W Jones, 1989, Refrigerasi dan Pengkondisian Udara. Edisi kedua, Alih bahasa Suratman Hara, Penerbit Erlangga, Jakarta 